\title{
Ovarian Metastasis of ALK Translocation-Positive Lung Adenocarcinoma: A Case Report
}

\author{
(1) Şener GEZER' ${ }^{1}$, (1) Devrim ÇABUK, ${ }^{2}$ (D) Lale AKSOY' , (D) Seda Duman ÖZTÜRK ${ }^{3}$, \\ (1) Sevgiye Kaçar ÖZKARA ${ }^{3}$, (1) İzzet YÜCESOY'
}

\begin{abstract}
'Department of Obstetrics and Gynecology, Kocaeli University, Faculty of Medicine, Kocaeli-Turkey ${ }^{2}$ Department of Medical Oncology, Kocaeli University, Faculty of Medicine, Kocaeli-Turkey

${ }^{3}$ Department of Pathology, Kocaeli University, Faculty of Medicine, Kocaeli-Turkey
\end{abstract}

\section{Introduction}

Metastatic tumors of the ovary usually originate from the gastrointestinal tract and the breast. Ovarian metastasis of lung cancer is substantially rare and only 0.4 $1 \%$ of cases with lung cancer develop ovarian metastasis.[1] Adenocarcinomas account for approximately $34 \%$ of these metastases. [2] In the literature, only seven ovarian metastases have been reported in adenocarcinoma histology with ALK gene rearrangement mutation.[3-9] In these patients, surgical resection is often performed to confirm the origin of the ovarian tumor. On the other hand, the role of surgery in diagnosis and treatment is controversial and the management should be individualized.

\section{Case Report}

A 37-year-old Gravida 4, Parity 3, Abort 1, the patient was admitted to Kocaeli University Hospital with a prolonged cough complaint. Her medical history was unremarkable, and she had no history of smoking. Computerized tomography scan revealed a $4 \times 5 \mathrm{~cm}$ mass in the distal left main bronchus, pleural metastasis, mediastinal lymphadenopathy, and multiple bone metastases. Transbronchial biopsy was performed from the lesion during fiberoptic bronchoscopy, and the pathology report of the biopsy specimen showed lung adenocarcinoma. Real-time PCR analysis (Rotor-Gene Q, Diatech Pharmacogenetics Easy) detected $31 \%$ Echinoderm microtubule-associated protein-like 
four (EML-4) ALK mutation and crizotinib therapy was started. The patient's cranial magnetic resonance imaging revealed lesions compatible with metastasis in the right superior temporal gyrus and in the posterior left cingulate gyrus measuring $10 \times 11 \mathrm{~mm}$ and $4 \mathrm{~mm}$, respectively (Fig. 1a). The patient received stereotaxic radiotherapy for intracranial metastasis at a dose of 1800cGy. Positron Emission Tomography-Computed Tomography (PET-CT) showed a positive response to treatment for the lung, mediastinum and skeletal metastases at the 5th-month follow-up. However, abdominal ultrasonography revealed a $110 \times 80 \times 130 \mathrm{~mm}$ left adnexial multilocular, septate, cystic mass with a solid component and widespread ascites in the abdomen. The serum Ca-125 value was $1789 \mathrm{U} / \mathrm{ml}$. Laparotomic staging surgery was performed. Pathological examination revealed metastasis of lung adenocarcinoma in the left ovary, right external iliac and right internal iliac lymph nodes (Fig. 1b). Immunohistochemical examination demonstrated strong nuclear staining with Thy-
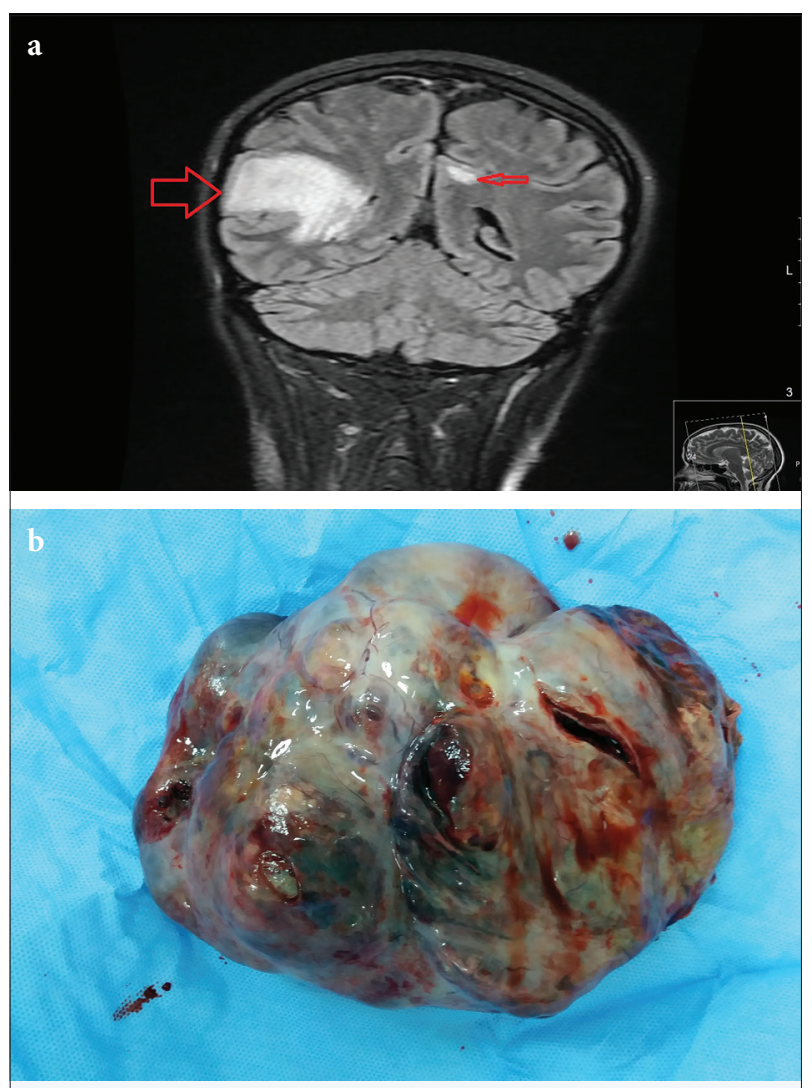

Fig. 1. (a) Cranial magnetic resonance imaging. Thick arrow indicates right temporal metastasis; thin arrow indicates metastasis in the left posterior cingulate gyrus. (b) Macroscopic view of the left ovarian mass.
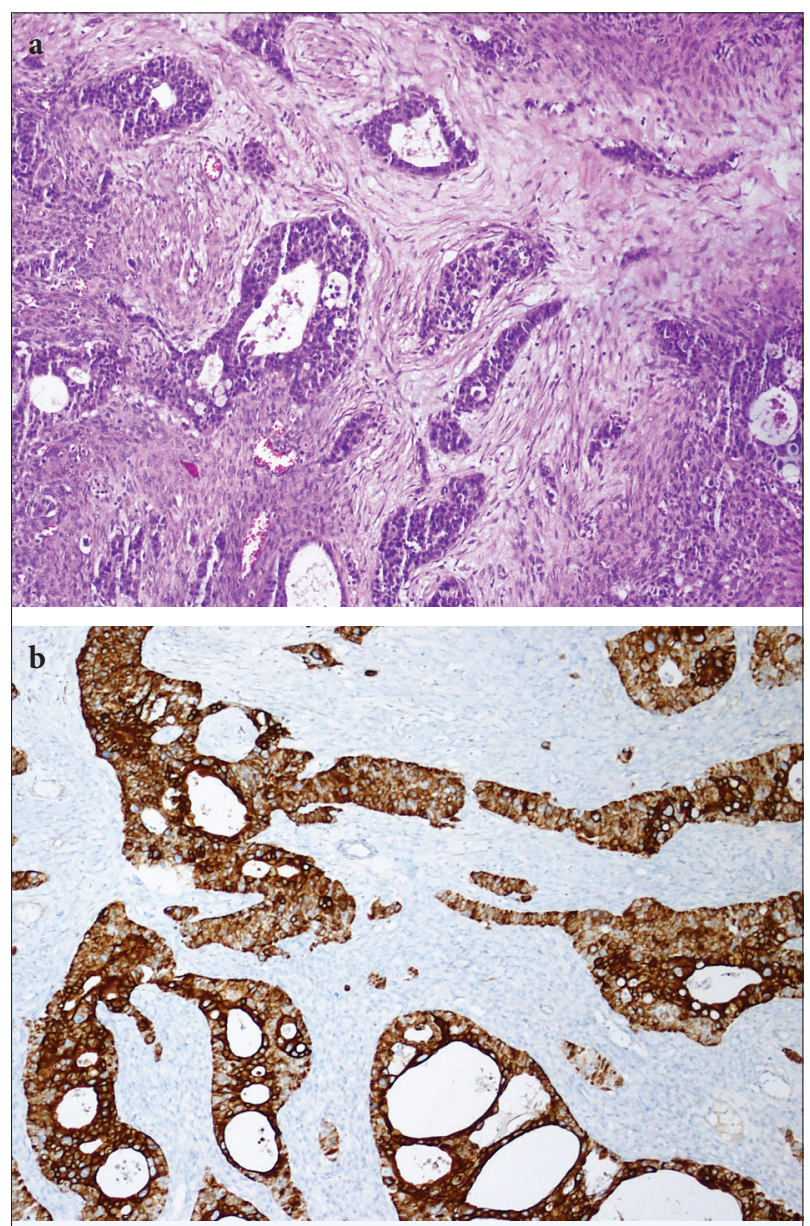

Fig. 2. (a) Focal strong nuclear positive immunostaining with TTF-1 for lung carcinoma (100x). (b) Diffuse strong cytoplasmic staining with cytokeratin (CK)-7 (100x).

roid Transcription Factor-1 (TTF-1) (Fig. 2a), Caudal Homeobox 2 (CDX2) and strong cytoplasmic staining with cytokeratin-7 (CK-7) (Fig. 2b) despite negative staining with p53, WT-1, cytokeratin-20 (CK-20) and Napsin-A. The patient is still on crizotinib therapy with no evidence of new metastases at the end of a one-year follow-up.

\section{Discussion}

Driver mutations may occur in the genes of signal transduction proteins. The presence of these mutations provides a growth advantage to cancer cells, and generally, more than one driver mutation is not detected in a tumor at the same time. Detection of driver gene mutations in non-small cell lung cancer (N-SCLC) has been implicated in the diagnosis and selection of appropriate treatment.[10] 
EGFR mutations have been associated with brain metastasis,[11] also ALK gene rearrangement has been associated with liver and pleural metastasis.[12] In addition, EML-4 ALK mutations are less common than EGFR mutations in N-SCLC.[13] Ovarian metastasis has been reported in seven ALK-positive N-SCLC patients in the literature. Ovarian metastasis developed during follow-up in four of the seven patients and it was detected at the first presentation in the remaining three patients. Five patients underwent ovarian resection and one patient received adjuvant alectinib therapy, and five patients started to receive crizotinib treatment. One patient refused to receive treatment and was lost to follow-up. Except for this patient, all patients had a mean follow-up time of 27.5 months. Resection of the metastatic tumor is controversial. Some authors claim that ovarian metastasis can be eradicated completely with alectinib or crizotinib treatment. Also, they advocate that attempts that increase morbidity should be avoided.[9] However, in our patient, ovarian metastasis developed under crizotinib therapy and treated with surgery, which is contrary to this view. Considering that the treatment given for primary ovarian cancer does not provide a benefit on N-SCLC metastasis, it is essential to perform surgery for diagnosis and therapy. Crizotinib is a first-class ALK tyrosine kinase inhibitor and has been shown to be superior compared to standard chemotherapy in two phase-3 studies. $[14,15]$

Immunohistochemistry (IHC) is an important adjunct tool in distinguishing ovarian metastatic tumors. Positive TTF-1 and CK-7, and negative CK-20 immunohistochemical staining is required for differentiating lung carcinoma metastasis from primary ovarian malignancy.[16] Also, Napsin-A is a good marker for the diagnosis of lung adenocarcinoma because it could only be detected in alveolar macrophages and pneumocytes.[17]

Further research is needed to analyze the correlation between ALK rearrangement and the metastatic behavior to the ovary or the adnexal area. ALK driver mutations will be more important in the near future for diagnosis and patient-based individualized treatment of N-SCLC metastases.

\section{Conclusion}

Ovarian metastasis of N-SCLC is substantially rare. Using driver gene mutations, such as ALK, will be more important in the patient-based individualized treatment of N-SCLC and its metastases. However, there is a need for more case series due to the limited number of ovarian metastasis of ALK-positive N-SCLC in the literature.
Informed consent: Informed consent was obtained from the patient in this study.

Peer-review: Externally peer-reviewed.

Conflict of Interest: No conflict of interest.

Authorship contributions: Concept - Ş.G., İ.Y.; Design - Ş.G.; Supervision - İ.Y., D.Ç., S.K.Ö.; Materials - S.D.Ö., L.A.; Data collection \&/or processing - L.A.; Analysis and/or interpretation - S..G.; Literature search - S..G.; Writing - S..G.; Critical review - Ş.G., S.K.Ö.

\section{References}

1. Fujiwara K, Ohishi Y, Koike H, Sawada S, Moriya T, Kohno I. Clinical implications of metastases to the ovary. Gynecol Oncol 1995;59(1):124-8.

2. Irving JA, Young RH. Lung carcinoma metastatic to the ovary: a clinicopathologic study of 32 cases emphasizing their morphologic spectrum and problems in differential diagnosis. Am J Surg Pathol 2005;29(8):997-1006.

3. Fujiwara A, Higashiyama M, Kanou T, Tokunaga T, Okami J, Kodama K, et al. Bilateral ovarian metastasis of non-small cell lung cancer with ALK rearrangement. Lung Cancer 2014;83(2):302-4.

4. Lee KA, Lee JS, Min JK, Kim HJ, Kim WS, Lee KY. Bilateral Ovarian Metastases from ALK Rearranged Non-Small Cell Lung Cancer. Tuberc Respir Dis (Seoul) 2014;77(6):258-61.

5. Mushi RT, Yang Y, Cai Q, Zhang R, Wu G, Dong X. Ovarian metastasis from non-small cell lung cancer with ALK and EGFR mutations: A report of two cases. Oncol Lett 2016;12(6):4361-66.

6. Wang $\mathrm{W}, \mathrm{Wu} \mathrm{W}$, Zhang Y. Response to crizotinib in a lung adenocarcinoma patient harboring EML4-ALK translocation with adnexal metastasis: A Case Report. Medicine (Baltimore) 2016;95(30):e4221.

7. Jing X, Li F, Meng X, Liu Z, Yu J, Liu B. Ovarian metastasis from lung adenocarcinoma with ALK-positive rearrangement detected by next generation sequencing: A case report and literatures review. Cancer Biol Ther 2017;18(5):279-84.

8. West AH, Yamada SD, MacMahon H, Acharya SS, Ali $\mathrm{SM}, \mathrm{He} \mathrm{J}$, et al. Unique metastases of ALK mutated lung cancer activated to the adnexa of the uterus. Case Rep Clin Pathol 2014;1(2):151-4.

9. Sasano $\mathrm{H}$, Sekine A, Hirata T, Iwamoto K, Itou Y, Itani $\mathrm{H}$, et al. Ovarian Metastases from ALK-rearranged Lung Adenocarcinoma: A Case Report and Literature Review. Intern Med 2018;57(22):3271-75.

10. National Comprehensive Cancer Network (NCCN) Clinical Practice Guidelines in Oncology: Non-Small Cell Lung Cancer. NCCN 2017 v3. Accessed 10 Feb- 
ruary 2019. https://www.nccn.org/professionals/physician_gls/pdf/nscl.pdf.

11. Sekine A, Kato T, Hagiwara E, Shinohara T, Komagata $\mathrm{T}$, Iwasawa $\mathrm{T}$, et al. Metastatic brain tumors from nonsmall cell lung cancer with EGFR mutations: distinguishing influence of exon 19 deletion on radiographic features. Lung Cancer 2012;77(1):64-9.

12. Doebele RC, Lu X, Sumey C, Maxson DA, Weickhardt $\mathrm{AJ}$, Oton $\mathrm{AB}$, et al. Oncogene status predicts patterns of metastatic spread in treatment-naive nonsmall cell lung cancer. Cancer 2012;118(18):4502-11.

13. Soda M, Choi YL, Enomoto M, Takada S, Yamashita Y, Ishikawa S, et al. Identification of the transforming EML4-ALK fusion gene in non-small-cell lung cancer. Nature 2007;448(7153):561-6.
14. Shaw AT, Kim DW, Nakagawa K, Seto T, Crinó L, Ahn MJ, et al. Crizotinib versus chemotherapy in advanced ALK-positive lung cancer. N Engl J Med 2013;368(25):2385-94.

15. Solomon BJ, Mok T, Kim DW, Wu YL, Nakagawa K, Mekhail T, et al. First-line crizotinib versus chemotherapy in ALK-positive lung cancer. N Engl J Med 2014;371(23):2167-77.

16. Yeh KY, Chang JW, Hsueh S, Chang TC, Lin MC. Ovarian metastasis originating from bronchioloalveolar carcinoma: a rare presentation of lung cancer. Jpn J Clin Oncol 2003;33(8):404-7.

17. Suzuki A, Shijubo N, Yamada G, Ichimiya S, Satoh M, Abe $S$, et al. Napsin A is useful to distinguish primary lung adenocarcinoma from adenocarcinomas of other organs. Pathol Res Pract 2005;201(8-9):579-86. 